\title{
Desmocollin-3 and Cancer
}

\author{
Bakulesh Khamar* \\ Cadila Pharmaceuticals Limited, Cadila Corporate Campus, India
}

Received: October 24,2017; Published: October 27, 2017

*Corresponding author: Bakulesh Khamar, Cadila Pharmaceuticals Limited, Cadila Corporate Campus, India, Tel: 0091-2718-225001;

E-mail: bmk@cadilapharma.co.in

\begin{abstract}
Desmocollin-3 [DSC3] is a transmembrane glycoprotein belonging to cadherin family of homophilic adhesion molecules, and is produced by the endoplasmic reticulum. DSC3 expression is seen in the suprabasal layer of stratified epithelium. DSC3 is a p53 responsive gene and can be detected by microarray. DSC3 protein expression is associated with expression of wild type p53 expression and can be detected by immune histochemistry. DSC3 protein is expressed on the surface of normal tissues. In proliferative tissues like, fetal and cancer, DSC3 protein is also seen in cytoplasm besides on cell surface. Expression of DSC3 is used as a diagnostic biomarker to differentiate squamous NSCLC from adenocarcinoma of lung. DSC3 expression is also seen in ovarian cancer, melanoma, colorectal cancer, cervical cancer, and meningioma cancer arising from oral cavity.

Expression of wild type p53 is associated with expression of DSC3. Chemotherapy, radiotherapy, targeted therapy [tyrosine kinase inhibitors], hypo methylating agents are known to induce expression of DSC3 in DSC3 negative cancers. As a homophilic adhesion molecule, it provides a unique opportunity for active immunotherapy by inducing DSC3 on surface of immune cells. CADI-05 is one such immunotherapy. It is found useful in management of squamous NSCLC and ovarian cancer when used with chemotherapy. It improves response rate and survival. As a mono therapy, it induces remission in melanoma and bladder cancer.
\end{abstract}

Keywords: Desmocollin- NSCLC; Cancer; CADI-05; Biomarker; Immunotherapy

Abbreviations: DSC3: Desmocollin-3; NSCLC: Non-small cell lung cancer

\section{Introduction}

Desmocollin-3[DSC3] is one of the adhesion molecules of cadher in super family found in desmosome and is a major adhesive force of epithelial cells [1-6]. DSC3 is a transmembrane calcium-dependent glycoprotein produced by the endoplasmic reticulum,encoded by the DSC3 gene. DSC3 is expressed, mainly in basal and immediate suprabasal layers of the stratified squamous epithelia [7] like buccal mucosa, esophagus, cervix, fore skin tongue, trachea etc. [3,8]. As an adhesion molecule, DSC3 provides homophilic adhesion i.e. cells expressing DSC3 will adhere to each other at the site of expression but not with others; it also works as a receptor as well as ligand to participate in cell signaling [9].

\section{P53 and Desmocollin-3}

DSC3 is one of the p53-responsive gene [1-11]. p53 is reported to be an upstream to DSC3. Expression of DSC3 gene is associated with expression of wild type of p53 and depends on the methylation status of the DSC3 DNA in the p53 binding site [10,11]. p53 expression in cancer is known to be altered by mutation or deletion of the p53 gene, with mutation of p53 being the most common event in human cancer [12]. Besides deletion and mutation of p53, p53 target genes are also silenced by epigenetic silencing like DNA methylation [1-11]. Mutant p53 inactivates p63 and is also associated with down regulation of DSC3 [10]. p63 is a master regulator of epidermal gene transcription and plays an essential function in controlling epidermal development, cell proliferation, stratification and cell-matrix adhesion [13]. There are two main isoforms of p63, Tap63 and Delta Np63. Delta Np63 alpha isoform is the most abundantly expressed p63 isoform. Both p63 and delta Np63 are activator for desmocollin-3 gene [13]. Knockdown of p63 and delta Np63 results in marked reduction in expression of DSC3 without any effect on expression of another adhesion molecule E-cadherin [13].

\section{Desmocollin-3 and Cancer:}

Desmosomal abnormalities are seen in cancer, as are alterations in DCS3 expression. In many epithelial cancers, DSC3 expression either over expressed or absent. DSC3 expression is not seen in many cancers e.g. adenocarcinoma of lung, breast, prostate cancer wherein there is mutation of P53 or hyper methylation. DSC3 was first cloned from human bladder cancer cell line [14]. Its presence can be detected by microarray (gene) or immunehistochemistry (protein)

a. Lung Cancer: DSC3 is not seen in normal lung tissue [15]. DSC-3 gene is over expressed 58 fold compared to adenocarcinoma [16]. Immunohistochemistry reveals in lung cancer expression of DSC3 is seen at basal layers of tumor. DSC3 
expression is seen in around 30\% of cases [17]. DSC 3 expression is seen in squamous NSCLC and not in adenocarcinoma of lung. It is closely associated with p63 expression which is another marker used for differentiation of Squamous NSCLC from other varieties [18-20].

b. OvarianCancer: DSC3 is seen in around $85 \%$ of ovarian caners. Its expression seems to be dependent on FSH.

c. Melanoma: DSC3 is expressed in melanoma [21-24]. Its expression decreases with increased thickness and progression to metastatic melanoma [22].

d. Colorectal Cancer: DSC 3 expression is seen in $60 \%$ colon cancer and also seen in $40 \%$ of colorectal lesion metastatic to the liver $[10,25,26]$.

e. Bladder Cancer: DSC3 was first cloned from a bladder cancer cell line [14]. We have documented DSC3 expression in around $60 \%$ of bladder cancer irrespective of grade and stage of tumor.

f. Meningioma: DSC3 expression is described in around $60 \%$ of meningioma [21,27].

g. Chondrosarcoma: DSC3 gene expression is detected in 4 of the 5 chondrosarcoma cell lines [28]. h. Pediatric Acute Lymphoblastic Leukemia: DSC3 gene is described to be over expressed in all TEL-AML1 subtype of paediatric acute lymphoblastic leukemia [29].

i. Skin Tumors: Loss of DSC3 is seen with tumour development and progression [30] and is associated with increase in K-Ras induced skin tumors [31].

j. Oral squamous cell carcinoma: Oral mucosa normally expresses DSC3. However development of oral Squamous cell carcinoma is associated with reduction or absence of DSC3 expression. This reduction/absence of DSC3 expression was associated with higher histological grade (moderately or poorly differentiated) [32].

k. Breastcancer: DSC3 is expressed in a normal breast but is down-regulated in breast cancer cell lines and primary breast tumors at protein as well as gene level [3,33]. The loss of DSC3protein expression is more likely to be aberrant methylation of rather than gene deletion or gross rearrangement of the gene [3].

1. Prostatecancer: DSC3 is expressed in normalprostate as well asbenign prostate tumors but is absent in prostate cancer due to hyper methylation [34].

Table 1: Sensitivity of DSC3 for squamous NSCLC.

\begin{tabular}{|c|c|c|c|c|c|c|c|}
\hline \multirow{2}{*}{ S. No } & \multirow{2}{*}{ Reference } & \multicolumn{2}{|c|}{ Squamous } & \multicolumn{2}{c|}{ Adenocarcinoma } & \multicolumn{2}{c|}{ Large cell carcinoma } \\
\cline { 3 - 7 } & & DSC-3+ve & DSC-3 & DSC-3 +ve & DSC-3 & DSC-3 +ve & DSC-3 \\
\cline { 3 - 7 } & & $/$ Total & + +ve\% & $/$ Total & $1.0 \%$ & $1 / 60$ & $1.2 \%$ \\
\hline 1 & Warth et al. [7] & $425 / 456$ & $93.2 \%$ & $5 / 530$ & $0 / 110$ & $0 \%$ & - \\
\hline 2 & Kim et al. [8] & $156 / 171$ & $91 \%$ & $0 / 157$ & $0 \%$ & - \\
\hline 3 & Tsuta et al. [9] & $109 / 150$ & $72.70 \%$ & $0 / 29$ & $0 \%$ & $12-\mathrm{Feb}$ & $16.70 \%$ \\
\hline 4 & Righi et al. [10] & $13 / 16$ & $86.70 \%$ & $1 / 40$ & $2.50 \%$ & $28 / 69$ & $40.60 \%$ \\
\hline 5 & Monica et al. & $24 / 24$ & $100 \%$ & $6 / 866$ & $0.69 \%$ & $31 / 141$ & $11.70 \%$ \\
\hline
\end{tabular}

\section{Desmocollin-3 as a diagnostic biomarker:}

a. Squamous NSCLC: DSC3 is used as a diagnostic biomarker to differentiate Squamous NSCLC from adenocarcinoma of lung [35-42]. DSC3 is more specific for squamous NSCLC compared to p63 as p63 is also expressed in Adenocarcinoma. DSC3 gene is up-regulated in squamous NSCLC and down regulated in adenocarcinoma [43]. Specificity of DSC3 is 100\% while sensitivity is variable [18-20,44,45] and varies with differentiation of tumor. Maximum sensitivity is seen in highly differentiated tumors and is lowest for poorly differentiated Squamous NSCLC. Sensitivity of DSC3 for squamous NSCLC is $93.2 \%$ in large cohort of 426 but drops to $59 \%$ in poorly differentiated squamous NSCLC (Table 1). DSC3 expression in NSCLC is also not related to stage or histologic grade [17] of a disease [46]. b. Paediatric Acute Lymphoblastic Leukaemia: DSC3 gene expression can be used to differentiate TEL-AML1 from other subtypes of paediatricacute lymphoblastic leukaemia [29].

\section{Desmocollin-3 as a prognostic biomarker}

a) NSCLC: In spite of squamous NSCLC having poor prognosis,smaller clinical trials suggest that DSC3 expressing tumors are likely to have better survival compared to DSC3 negative tumors and may serve as a potential prognostic marker [1,17].

b) Colorectalcancer: Tumors with methylated DSC3 DNA were significantly correlated to a worse clinical outcome than unmethylated tumors. The methylation status of DSC3 DNA was not linked to any of clinical pathological parameters including 
age, gender, size of tumor, tumor grading, and tumor stage in these patients [10].

c) Prostatecancer: Loss of DSC3 predicts poor prognosis.

\section{Effect of therapeutic intervention on DSC3 expression:}

a. DNA damaging agents: Expression of wild type of p53 can also be increased or induced by DNA damaging agents like radiotherapy, doxorubicin, cisplatin, paclitaxel, gemcitabine etc. Expressionof wild type p53 is sufficient to induce expression of DSC3 in breast, colorectal and lung cancers in absence of DSC3 DNA methylation [1,10,11]. Expression of wild typep53 converts DSC3 negative tumors in to DSC3 positive.

b. Tyrosine Kinase inhibitors: DSC3 expression has reciprocal relationship with ERK of MAPK family.Decreased ERK is seen following successful treatment with tyrosine kinase inhibitors. EGFR inhibitor like gefitinib converts DSC3 negative EGFR mutant adenocarcinoma of lung in to DSC3 positive.

c. Hypomethylating/Demethylating agents: DSC3 hypermethylation is seen in prostate and breast cancerleading to lack of DSC3 expression by this tumors $[3,6,33]$. Hypomethylating/Demethylating agents like azacytidine convert DSC3 negative tumors to DSC3 Cadi-05[3,47].

\section{Desmocollin-3 and immunotherapy:}

DSC3 is a homophilic adhesion molecule, which works as a receptor as well as a ligand. This provides an opportunity to develop an active immunotherapy for DSC3 expressing tumors by inducing DSC3 on surface of tumor targeting activated immune cells. CADI05 is one such active immunotherapy. It induces DSC3 expression on immune cells and also induces Th1 type of immune response through TLR2 agonist activity [48]. Cadi-05 increases tumor infiltrating immune cells [49] and found useful in management of cancers as a monotherapy for small size tumors [49,50]. As combination therapy with checkpoint modulators, radiotherapy as well as chemotherapy, Cadi-05 improves outcome of large size tumors [51].

Cadi-05 achieves and maintains remission in melanoma as well as in bladder cancer as a systemic monotherapy [52, 53]. In combination with chemotherapy, it improves response rate. Responses achieved are durable and results in improved survival. Identical results are seen when combined with radiotherapy. It is expected that combination with anti PD-L1 therapy will result in significant improvement in no. of durable responses.

\section{Conflict of Interest}

Bakulesh Khamar is an employee of Cadila Pharmaceuticals Limited.

\section{References}

1. Cui T, Chen Y, Yang L, Knösel T, Huber O, et al. (2012) The p53 target gene desmocollin 3 acts as a novel tumor suppressor through inhibiting EGFR/ERK pathway in human lung cancer. Carcinogenesis 33(12): 2326-2333.

2. Garrod DR, Merritt AJ, Nie Z (2002) Desmosomal cadherins. Curr Opin Cell Biol 14(5): 537-545.
3. Oshiro MM, Kim CJ, Wozniak RJ, Junk DJ, Muñoz-Rodríguez JL, et al. (2005) Epigenetic silencing of DSC3 is a common event in human breast cancer. Breast Cancer Res 7(5): R669-R680.

4. Akat K, Mennel HD, Kremer P, Gassler N, Bleck CK (2003) Molecular characterization of desmosomes in meningiomas and arachnoidal tissue. ActaNeuropathol 106(4): 337-347.

5. Wheelock MJ, Soler AP, Knudsen KA, et al. (2001) Cadherin junctions in mammary tumors. J Mammary Gland Biol. Neoplasia 6(3): 275-285.

6. Wang L, Liu T, Wang Y, Cao L, Nishioka M, et al. (2007) Altered expression of desmocollin 3, desmoglein 3, and beta-catenin in oral squamous cell carcinoma: correlation with lymph node metastasis and cell proliferation. Virchows Arch 451(5): 959-966.

7. Nuber UA, Schäfer S, Stehr S, Rackwitz HR, Franke WW (1996) Patterns of desmocollin synthesis in human epithelia: immunolocalization of desmocollins 1 and 3 in special epithelia and in cultured cells. Eur J Cell Biol 71(1): 1-13.

8. King IA, Sullivan KH, Bennett R, Buxton RS (1995) The desmocollins of human foreskin epidermis: identification and chromosomal assignment of a third gene and expression patterns of the three isoforms. J Invest Dermatol 105(3): 314-321.

9. AJ Freemont, JA Hoyland (1996) Cell adhesion molecules J ClinPathol: MolPathol 49: M32 1-M330.

10. Cui T, Chen Y, Yang L, Knösel T, Zöller K, et al. (2011) DSC3 expression is regulated by p53, and methylation of DSC3 DNA is a prognostic marker in human colorectal cancer. Br J Cancer 104(6): 1013-1019.

11. Oshiro MM, Watts GS, Wozniak RJ, Junk DJ, Munoz Rodriguez JL, et al. (2003) Mutant p53 and aberrant cytosine methylation cooperate to silence gene expression. Oncogene 22(23): 3624-3634.

12. Freed Pastor WA, Prives C (2012) Mutant p53: one name, many proteins. Genes Dev 26(12): 1268-86.

13. Ferone G, Mollo MR, Thomason HA, Antonini D, Zhou H, et al. (2013) p63 control of desmosome gene expression and adhesion is compromised in AEC syndrome. Hum Mol Genet 22(3): 531-543.

14. Kawamura K, Watanabe K, Suzuki T, Yamakawa T, Kamiyama T, et al. (1994) cDNA cloning and expression of a novel human desmocollin. J Biol Chem 269(42): 26295-26230.

15. Boelens MC, van den Berg A, Vogelzang I, Wesseling J, Postma DS, et al. (2007) Differential expression and distribution of epithelial adhesion molecules in non-small cell lung cancer and normal bronchus. J ClinPathol 60(6): 608-614.

16. Zhan C, Yan L, Wang L, et al. Identification of immunohistochemical markers for distinguishing lung adenocarcinoma from squamous cell carcinoma. Journal of Thoracic Disease 7(8): 1398-1405.

17. Cui T, Chen Y, Yang L, Mireskandari M, Knösel T, et al. Diagnostic and prognostic impact of desmocollins in human lung cancer. J ClinPathol 65(12): 1100-1106.

18. Warth A, Muley T, Herpel E, Meister M, Herth FJ, et al. (2012) Large-scale comparative analyses of immunomarkers for diagnostic subtyping of non-small-cell lung cancer biopsies. Histopathology 61(6): 1017-1025.

19. Tsuta K, Tanabe Y, Yoshida A, Takahashi F, Maeshima AM, et al. (2011) Utility of 10 immunohistochemical markers including novel markers (desmocollin-3, glypican 3, S100A2, S100A7, and Sox-2) for differential diagnosis of squamous cell carcinoma from adenocarcinoma of the Lung. J Thorac0ncol 6(7): 1190-1199.

20. Monica V, Ceppi P, Righi L, Tavaglione V, Volante M, et al. (2009) Desmocollin-3: a new marker of squamous differentiation in undifferentiated large-cell carcinoma of the lung. Mod Pathol 22(5): 709-717.

21. Hum Pathol (2011) 42(3):409-18.

22. Jaeger J, Koczan D, Thiesen HJ, Ibrahim SM, Gross G, et al. (2007) Gene expression signatures for tumor progression, tumor subtype, and tumor 
thickness in laser-microdissected melanoma tissues. Clin Cancer Res 13(3): 806-815.

23. Riker AI, Enkemann SA, Fodstad O, Liu S, Ren S, et al. (2008) The gene expression profiles of primary and metastatic melanoma yields a transition point of tumor progression and metastasis. BMC Med Genomics 1:13.

24. Winnepenninckx V, Lazar V, Michiels S, Dessen P, Stas M, et al. Gene expression profiling of primary cutaneous melanoma and clinical outcome. J Natl Cancer Inst 98(7): 472-482.

25. Khan K, Hardy R, Haq A, Ogunbiyi O, Morton D, et al. (2006) Desmocollin switching in colorectal cancer. Br J Cancer 95(10): 1367-1370.

26. Knösel T, Chen Y, Hotovy S, Settmacher U, Altendorf-Hofmann A, et al. (2012) Loss of desmocollin 1-3 and homeobox genes PITX1 and CDX2 are associated with tumor progression and survival in colorectal carcinoma. Int J Colorectal Dis 27(11): 1391-1399.

27. US patent application 200410076955.

28. Akat K, Mennel HD, Kremer P, Gassler N, Bleck CK, et al. (2003) Molecular characterization of desmosomes in meningiomas and arachnoidal tissue. ActaNeuropathol 106(4): 337-347.

29. Fitzgerald MP, Gourronc F, Teoh ML, Provenzano MJ, Case AJ, et al. (2011) Human Chondrosarcoma Cells Acquire an Epithelial-Like Gene Expression Pattern via an Epigenetic Switch: Evidence for MesenchymalEpithelial Transition during Sarcomagenesis. Sarcoma 2011: 598218.

30. Chen J, O'Shea C, Fitzpatrick JE, Koster MI, Koch PJ (2012) Loss of Desmocollin 3 in skin tumor development and progression. MolCarcinog 51(7): 535-545.

31. Ross ME, Zhou X, Song G, Shurtleff SA, Girtman K, et al. (2003) Classification of pediatric acute lymphoblastic leukemia by gene expression profiling. Blood 102(8): 2951-2959.

32. Klus GT, Rokaeus N, Bittner ML, Chen Y, Korz DM, et al. (2001) Downregulation of the desmosomal cadherin desmocollin 3 in human breast cancer. Int J Oncol 19(1): 169-174.

33. Nuber UA, Schäfer S, Stehr S, Rackwitz HR, Franke WW (1996) Patterns of desmocollin synthesis in human epithelia: immunolocalization of desmocollins 1 and 3 in special epithelia and in cultured cells. Eur J Cell Biol 71(1): 1-13.

34. Pan J, Chen Y, Mo C, Wang D, Chen J, et al. (2014) Association of DSC3 mRNA down-regulation in prostate cancer with promoter hyper methylation and poor prognosis 9(3): e92815.

35. Weissferdt A, Kalhor N, Rodriguez Canales J, Fujimoto J, Wistuba II, et al. (2016) Spindle cell and pleomorphic (sarcomatoid) carcinomas of the lung: animmuno histochemical analysis of 86 cases. Hum Pathol 59: 1-9.

36. Bir F, Çeliker D, Evyapan BF, Yaren A, Edirne T (2016) New immune histochemical markers in the differential diagnosis of non small cell lung carcinoma. Turk J Med Sci 46(6): 1854-1861.

37. EzzatNel S, Tahoun N. The role of Napsin-A and Desmocollin-3 in classifying poorly differentiating non-small cell lung carcinoma. J Egypt Natl Canc Inst 28(1): 13-22.

38. Kawai T, Tominaga S, Hiroi S, Kameda K, Ogata S, et al. Expressions of Thyroid Transcription Factor-1, Napsin A, p40, p63, CK5/6 and Desmocollin-3 in Non-Small Cell Lung Cancer, as Revealed by Imprint Cytology Using a Malinol-Based Cell-Transfer Technique. ActaCytol 59(6): 457-64.

39. Righi L, Vavalà T, Rapa I, Vatrano S, Giorcelli J, et al. (2014) Impact of nonsmall-cell lung cancer-not otherwise specified immune phenol typing on treatment outcome. J ThoracOncol 9(10): 1540-1546.
40. Tatsumori T, Tsuta K, Masai K, Kinno T, Taniyama T, et al. (2014) p40 is the best marker for diagnosing pulmonary squamous cell carcinoma: comparison with p63, cytokeratin 5/6, desmocollin-3, and sox2. Appl Immunohistochem Mol Morphol 22(5): 377-382.

41. Rossi G, Mengoli MC, Cavazza A, Nicoli D, Barbareschi M, et al. (2014) Large cell carcinoma of the lung: clinically oriented classification integrating immunohistochemistry and molecular biology. Virchows Arch 464(1): 61-68.

42. Barbareschi M, Cantaloni C, Del Vescovo V, Cavazza A, Monica V, et al. (2011) Heterogeneity of large cell carcinoma of the lung: an immunophenotypic and miRNA-based analysis. Am J ClinPathol 136(5): 773-782.

43. Rohrbeck A, Neukirchen J, Rosskopf M, Pardillos GG, Geddert H, et al. (2008) Gene expression profiling for molecular distinction and characterization of laser captured primary lung cancers. J Transl Med $6: 69$.

44. Righi L, Graziano P, Fornari A, Rossi G, Barbareschi M, et al. (2011) Immunohistochemical subtyping of nonsmall cell lung cancer not otherwise specified in fine-needle aspiration cytology: a retrospective study of 103 cases with surgical correlation. Cancer 117(15): 34163423.

45. Kim GY, Lim SJ, Kim WS, Lee GK. (2012) A Minimal Immunohistochemical Panel for Subtyping Poorly Differentiated Non-Small Cell Lung Carcinoma: A Tissue Microarray Study Simulating Small Biopsy Conditions. J Lung Cancer 11(1): 21-32.

46. Masai K, Tsuta K, Kawago M, Tatsumori T, Kinno T, et al. (2012) Expression of Squamous Cell Carcinoma Markers and Adenocarcinoma Markers in Primary Pulmonary Neuroendocrine Carcinomas. Appl Immunohistochem Mol Morphol 21(4): 292-297.

47. Wozniak RJ, Klimecki WT, Lau SS, Feinstein Y, Futscher BW (2007) 5-Aza2 '-deoxycytidine-mediated reductions in G9A histone methyltransferase and histone $\mathrm{H} 3 \mathrm{~K} 9$ di-methylation levels are linked to tumor suppressor gene reactivation. Oncogene 26(1): 77-90.

48. Belani C, Desai D, Khamar B (2011) Open-label, randomized multicenter phase II clinical trial of a toll-like receptor-2 (TLR2) agonist mycobacterium w (Cadi-05) in combination with paclitaxel plus cisplatin versus paclitaxel plus cisplatin in advanced non-small cell lung cancer (NSCLC). J ClinOncol 29: suppl abstr 7501.

49. Ahmad F, Mani J, Kumar P, Haridas S, Upadhyay P, et al. (2011) Activation of anti-tumor immune response and reduction of regulatory T cells with Mycobacterium indicuspranii (MIP) therapy in tumor bearing mice PLoS One 6(9): e25424.

50. Rakshit S, Ponnusamy M, Papanna S, Saha B, Ahmed A, et al. (2012) Immunotherapeutic efficacy of Mycobacterium indicuspranii in eliciting anti-tumor T cell responses: critical roles of IFN $\gamma$. Int J Cancer 130(4): 865-875.

51. Khamar B (2006) Poly-TLR agonist poly antigenic vaccine cadi-05 in advanced bladder cancer. In: Proceedings of the 97th Annual Meeting of the American Association for Cancer Research Washington, DC. Philadelphia (PA): AACR; P 682.

52. Khamar B, O’Donell M, Belani C. Intradermal toll like receptor-2 (TLR2) agonist mycobacterium $\mathrm{w}$ (Cadi-05) in the treatment of BCG refractory non muscle invasive transitional cell carcinoma of bladder. In: Proceedings of 27th Annual meeting of Society for Immunotherapy of Cancer (SITC); North Bethesda, MD.

53. Mosca P, Nair S, Ayre S, Wenjing S, Sherrine E, et al. Immunologic Therapy with Cadi-05 for the Treatment of Advanced Melanoma. 


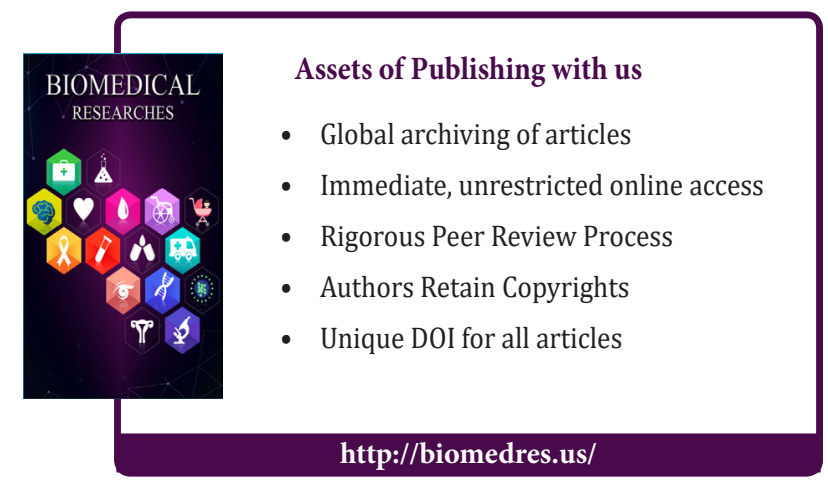

